\title{
Determinants of Commercialization of Agricultural Products in East and West Gojjam, and Awi Zones, Amahara Region, Ethiopia
}

\author{
Tadesse Asmare Gebrie ${ }^{1}$ (MBA) \\ Debre Markos University, College of Business and Economics, Department of Management \\ P.O Box: 269 \\ Beza Muche Teka² (Ph D.) \\ Debre Markos University, College of Business and Economics, Department of Accounting and Finance \\ P.O.Box:269
}

\begin{abstract}
Agricultural commercialization is a process of involving the transformation from agricultural products for household subsistence to production for the market in orders to enhance the likelihood of the farmers. The objective of this study is to investigate the determinants of commercialization of agricultural products in the three zones of Amahara region. Both explanatory and causal types of research were applied and by review of previous empirical studies, a research questionnaire was developed for small holder farmers as a means of data collection. To address the objective of the study, 359 questionnaires were prepared and distributed to the respondents. The actual data collected from small holder farmers were analyzed by using binary logistic regression and the finding indicates that eleven predictor variables such as, marital status, education, family size, farm size, training, off farm income, access to extension, access to irrigation, access to private transportation, access to market information and price volatility have statistically significant effects on commercialization of agricultural products. Therefore, it is suggested that the identified problems are addressed through collaborative and deliberate action of both farmers and the government to bring sustainable solution to enhance commercialization of small holder farmer's in the study areas.
\end{abstract}

Keywords: Commercialization, logistic regression, determinant factors, Agricultural products, east \& west Gojjam zone

DOI: $10.7176 / \mathrm{JMCR} / 63-04$

Publication date: December $31^{\text {st }} 2019$

\section{INTRODUCTION}

In many countries, and essentially every less developed country (LDC), agriculture is the biggest single industry for their livelihood of societies. According to Kriesberg (1974), agriculture typically employs over $50 \%$ of the labour force in LDCs with industry and commerce dependent upon as a source of raw materials and as a market for manufactured goods. Dixie (1989) highlights that, the potential contribution of agricultural products and food marketing, towards attempting to improve rural incomes in developing countries including Ethiopia with regards to the case study. Majority of developing countries including Ethiopia, the population have been lived in rural areas and mainly dependents on subsistent agriculture products as a source of livelihood for their existence.

Govereh et al., (1999) define agricultural commercialization as "the proportion of agricultural production that is marketed. According to these researchers, agricultural commercialization aims to bring about a shift from production for solely domestic consumption to production dominantly market-oriented i.e. production for consumption to commercializing of agricultural products. According to (Sokoni2007), commercialization agricultural production is a process involving the transformation from production for household subsistence to production for the market. On the other hand, Agricultural commercialization is a process involving transformation of agriculture to market oriented production which tend to impacts income, consumption and nutritional setup of the farm households (Braun,1995) cited by Tirkaso,2013)

According to Von Braun et al. (1994), commercialization of subsistence agriculture takes many forms. They state that: "Commercialization can occur on the output side of production with increased marketed surplus, but it can also occur on the input side with increased use of purchased inputs to increase agricultural products to commercialize agricultural products. This is called traditional food crops are frequently marketed to a considerable extent for commercialization but it is low for participation. The countries of South Asia and much of Sub-Saharan Africa are at the lower end of the commercialization pathway (Norsida and Nawi, 2010).this means that sub Saharan Africa (including Ethiopia) and south Asia's agricultural commercialization were low. Dispute it, those countries economically they are developed; they are more participated for commercialization. Increased commercialization is not necessarily identical with expansion of the cash economy when there exists for considerable inland transactions and payments with food commodities for land use or laborers. Projections of 
production and marketing surplus of various farm produce in the Ethiopia exhibit that the commodities, which the marketing system will be required to handle in future, are quite large. The capacity to clean, grading, packing, processing and transporting would have to correspondingly expand to handle the additional marketed quantities. However, in Ethiopia, the development of agricultural marketing commercialization is at its infancy stage or in some places never introduced to facilitate the commercialization of agricultural products. Therefore, the objective of this study is to investigate the determinants of commercialization of agricultural products among small-holder farmers in the study area.

\section{Statement of the Problem /Rationalities of the study/}

Commercialization of smallholder agricultural products through increased participation in output markets has been promoted as one of the best strategy to address low agricultural productivity that has led to high levels of poverty and food insecurity among rural farming households in developing countries (Goletti, 2005, Jaleta et al.,2009, Olwande and Mathenge 2011, and Wickramasinghe \& Weinberger, 2013). Even the market liberalization policy agendas that were widely promoted in sub-Saharan Africa (SSA) in the 1980s and 1990s under structural adjustment programmes (SAPs) were broadly aimed at stimulating and enhancing agricultural commercialization for enhancing the livelihood of small holder farmers who are influenced by poverty. Though these market liberalization policies were aimed at opening up new market-led opportunities for economic growth, their results were mixed in most countries. Even to date, many smallholder producers continue to engage in subsistence agriculture and thus unable to benefit from commercialization opportunities presented by the liberalized markets (Barrett, 2008, Shiferaw et al., 2008, Siziba et. al., 2011).

Generally, the rural smallholder farmers do not have appropriate marketing system to participate in the agricultural product market and their commercialization rate remains low (Jayne et al.,2005). According to Jayne et al. (2005), only $2 \%$ of farmers sold approximately $50 \%$ of their maize product in Zambia, Mozambique and Kenya. Similarly (Ellis 2000) found that African farmers were able to sell only a smaller share of their production this means that they are not produced surplus agricultural products for commercialization. The study results of Gebreslassie et al. (2015) indicated that the average crop commercialization index in Tigray Regional State was about $19 \%$ of the total products in the study area which shows the livelihood of the smallholder farm households is almost subsistence oriented. Moreover, the crop commercialization index for cereals was lower than that of pulses and vegetable and fruits production, implying that in the dry land areas of Ethiopia, cereal production is more of subsistence nature than pulses and horticultural crops. Cash crop marketing systems are generally characterized by their well-defined producers, processors, and final consumers. The produce tends to flow with relative efficiency from one level to the next until it reaches the final consumer for modernizing agricultural product commercializing but is low in the case study due to different factors such as farmer's side and government side.

Different strategies have been made to enhance the productivity of farms and to improve the linkages between farmers and market-based on advanced technology (ATA, 2015). This research study area is fertile compared to its near neighboring zones and is comfortable for irrigated agriculture. The major crops in the study area include; teff, wheat, maize, barley, bean and variety of vegetables (CSA, 2007). According to CSA (2007) report, approximately $90 \%$ of the farmers are smallholders having farm size less than 2 hectare and produced wheat, teff, maize others. But still they use traditional means of production and cultivation which not only increases the cost however it reduces commercialization, this leads to reduce profitability of small holder farmers. Keeping in to account those problems and situations, the main aims of this study is to examine the main determinant factors that affect commercialization of agricultural products among small holder farmers in the study area.

\section{Hypotheses formulation}

Based on the review of literatures, the following research hypotheses were formulated for this study

H1: Marital Status has significant positive effect on commercialization of agricultural products.

H2: Gender has significant positive effect on commercialization of agricultural products.

H3: Age of the farmers have significant effect on commercialization of agricultural products.

H4: Educational levels of the farmers have a positive effect on commercialization of agricultural products.

H5: Family sizes have negative significant effects on commercialization of agricultural products.

H6: Farm experiences of small holder farmers have positive effects on commercialization of agricultural products.

H7: Farm size of households has positive effect on commercialization of agricultural products.

H8: Training the small holder framers has positive effects on commercialization of agricultural products.

H9: Access to market information for the farmers has positive effects on agricultural product of commercialization.

H10: Access to irrigation for the small holder farmers has positive effect on commercialization of agricultural products. 
H11: Availability of transportation for small holder farmers has positive significant effect on commercialization of agricultural products.

H12: Access to extension for the farmers has positive significant effect on commercialization of agricultural products.

H13: Off-farm income of the house hold has negative effect on commercialization of agricultural products.

H14: Access to credit for the farmer has positive significant effect on commercialization of agricultural products.

H15: Availability of land has a positive significant effect on commercialization of agricultural products.

H16: the availability of media has positive/negative significant effect on commercialization of agricultural products.

H17: Price volatility has negative effect on commercialization of agricultural products.

Definition of Variables Included in the Research Hypothesis

Marital status: it refers to the marital status of respondents included in household that measured using nominal scale

Gender: It refers to gender/sex of the individuals $(1=$ male and $0=$ female $)$

Age: It refers to the age of the respondent at the time of data collection measured in years.

Educational level: It refers to the educational status of the individual at the time of data collection measured using nominal scale

Family size: It refers to the member of the individuals to be included in the household measured in Numbers

Farm Size: It refers to the availability of land for farmers which is measured by number in Hectares

Farm experience: It refers to the numbers of years which the farmers are engaged in agriculture which is measured in years

Training: It refers to ways of acquiring skill or knowledge for increasing agricultural products and then to participate commercialization $(1=$ available and $0=$ not available $)$

Access to market information: It refers to acquire relevant information how to produce and participate for commercialization activities $(1=$ available and $0=$ not available)

Access to irrigation: It is refers to the availability of irrigation for enhancing agricultural products which is used for commercialization agricultural products $(1=$ available and $0=$ not available $)$

Availability of transportation: It refers the availability of transportation for enhancing commercialization which is dummy variables $(1=$ available and $0=$ not available $)$

Access to extension: It refers to the availability of extension package which is used for increased agricultural products and facilitating of commercialization which is dummy variables ( $1=$ available and $0=$ not available)

Off-farm income: It refers to the availability of additional income for the famers which is dummy variable $(1=$ available and $0=$ not available)

Access to credit: It refers to the availability of credits for small holder farmers to modernizing the agricultural products for market participation which is dummy variables $(1=$ available and $0=$ not available)

Media: It refers to the sources of information for the farmers to get new information regarding to the current marketing status which is dummy variable $(1=$ owned media, $0=$ not owned media)

Price volatility: It refers to the price fluctuation of agricultural products which is dummy variable $(1=$ fluctuated, $0=$ none fluctuated)

Agricultural commercialization: It refers to the abilities to participate for commercialization which is dummy variable with dichotomous response of 1 and $0,(1=$ participating for commercialization and $0=$ not participating for commercialization).

\section{RESEARCH METHODOLOGY}

Study Design: This study used a cross sectional research design. Moreover, the research was used an explanatory research type with an intention to investigate the determinants of commercialization of agricultural products of small holder farmers in East Gojjam, West Gojjam and Awi Zones.

Data Type and Sources: The study used both qualitative and quantitative data type that is collected from the small holder farmers in East Gojjam, West Gojjam and Awi Zones. For the better accomplishment of this research, it has used both primary and secondary sources of data.

Sample Design, total population and Sample size Determination: In this research Cluster sampling technique was used to reduce the sampling bias and error in taking a sample. If the total area of interest happens to be a big one, a convenient way in which a sample can be taken is to divide the area into a number of smaller nonoverlapping areas and then to randomly select a number of these smaller areas (usually called clusters), with the ultimate sample consisting of all (or samples of) units in these small areas or clusters (Kothari, 2004). In the study area there are around 1,265 kebelles. The sample size was calculated by the scientific formula given by Yamane (1967); $\boldsymbol{n}=\frac{N}{1+N(\boldsymbol{n}\}^{2}}$ where, e - level of precision, $\mathrm{n}-$ sample size and $\mathrm{N}-$ target population. In this 
study, the target population was 1,265 kebelles, because of homogeneity the level of precision was assumed to be $20 \%$ and the sample size was calculated using the above formula, given by Yamane, as follows:

$n=\frac{N}{1+N(\theta)^{2}} n=\frac{1265}{1+1265(0.2)^{2}} n=\frac{1205}{11.4}=24.5=25$

Therefore, from three zones, proportionate to their size, $25 \mathrm{kebelles}$ were used as a sample for this study. The sample kebelles from each zone was taken in proportion to the number of wereda's in each zone. East Gojjam zone $=(20 / 50) * 25=11$; West Gojjam zone $=(19 / 50) * 25=9$ and Awi zone $=(11 / 50) * 25=5$ kebelles. The sample kebelles should also be taken from a specified wereda. The 8 weredas were selected through lottery methods. The researchers have taken 4 woredas (Gozamen, DejenZuria, Enemay and Huletejuansie in east gojjam) 3 woredas (yilmanadensa, BurieZuria and Wenberma in West Gojjam ) and 1 woredas (AnkeshaGuagusa in Awi zone). On average in each kebelle there are 5,000 small holder farmers. So, in 25 kebelle's, there are around 125,000 small holder farmers. The number of small holder farmers to be contacted to be equal to:

$n=\frac{N}{1+N(a)^{2}} n=\frac{125,000}{1+125,000(0.05)^{2}} ; n=\frac{105,000}{818,5}=398.72=399$

Data Collection Instruments: In order to gather the relevant data which can meet the desired objective of this research, structured questionnaires (Both close end and open end questions) were prepared and administered by the data enumerators on small holder farmers.

Data Analyzing Techniques: The data analysis technique begins after the raw data is edited, coded, tabulated and summarized in a required form for analysis. This study was utilized econometric data analysis technique such as, binary logistic regression model was used to estimate parameters of the determinants of commercialization of agricultural products. The logistic regression done by using a statistical package called SPSS 24.00version.

Empirical Framework and Model Specifications: Agricultural commercialization means change from subsistence type of production to market oriented with the aim of profit maximization (Goletti, 2005). Commercialization is not only the selling of output but it also includes product choice and input use decisions that are based on profit maximization principle (Pingali and Rosegrant, 1995). It can occur on both sides, either on output side with increased output being marketed or input side with increased use of inputs (Von Braun, 1995). If the degree of commercialization is low, it refers to low output and vice versa. The use of modern tools and technology play an indispensable role in agricultural production, income generation and profit making (Goletti, 2005). In this study binary logistic regression analysis is a specialized form of regression that is formulated to predict and explain a binary (two group) categorical variable rather than a metric dependent measure. Therefore, when the dependent variable is categorical (binary) and the independent variables are metric or non-metric, binary logistic regression is appropriate (Hair et al., 2010). Logistic regression represents the two groups of interest as binary variables with values of zero and one. The index is therefore a value bound between 0 and 1 and cannot fall outside of this range; 0 indicates that a household did not commercialize in the crops output market at all while 1 indicating that a household is completely commercialized. Therefore, for this study, the binary logistic regression model wasexplained as follows:

$\mathrm{P}_{\mathrm{i}}=\mathrm{E}\left(\mathrm{Y}=1 / \mathrm{X}_{\mathrm{i}}\right)=\beta_{1}+\Sigma \beta_{\mathrm{i}} \mathrm{X}_{\mathrm{i}}$

Where, ' $\mathrm{Y}$ ' is the dependent (dichotomous) variable that takes 1 if individuals are using commercialization (included) and ' $\mathrm{X}$ ' represents the independent variables that have potential influence on $\mathrm{Y}$.

Therefore, from equation (1) above the probability of an individual's being included in a commercializing measured in terms of participation in the market can be represented by the following equation:

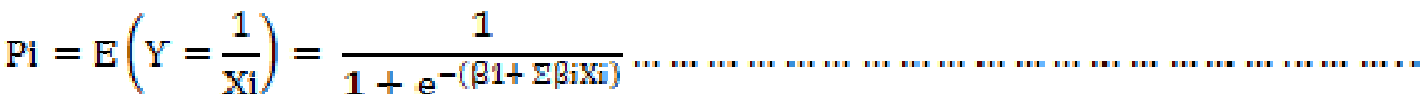

For ease of computation equation (2) can be rewritten as to the probability of market participation

$\mathrm{P}_{1}=\frac{1}{1+\mathrm{e}^{-z i}}=\frac{\mathrm{e}^{\mathrm{zi}}}{1+\mathrm{e}^{z i}}$

Where, $Z_{\mathrm{i}}=\beta_{1}+\Sigma \beta_{\mathrm{i}} \mathrm{X}_{\mathrm{i}}$

The Logit model on equation (3) above is known as the cumulative logistic distribution function. Thus, it is easy to verify that as $\mathrm{Z}_{\mathrm{i}}$ ranges from $-\infty$ to $+\infty, \mathrm{P}_{\mathrm{i}}$ ranges between 0 and 1 and that $\mathrm{P}_{\mathrm{i}}$ is nonlinearly related to $\mathrm{Z}_{\mathrm{i}}\left(\mathrm{i}\right.$.e., $\left.\mathrm{X}_{\mathrm{i}}\right)$, thus satisfying the requirements of logstic regression.

Estimation of the Logit model in this study takes in to account the following: (the probability that the farmers participating in market) is given by equation (3) above, and then the probability of an individual excluded from market participation will be $\left(1-\mathrm{P}_{\mathrm{i}}\right)$.

That is,

$1-\mathrm{P}_{\mathbf{i}}=\frac{1}{1+\mathrm{e}^{2 \mathrm{i}}} \ldots$ 
The equation can rewrite as:

$\frac{\mathrm{P}_{1}}{1-\mathrm{P}_{\mathrm{i}}}=\frac{1+\mathrm{e}^{z \mathrm{i}}}{1+\mathrm{e}^{-\mathrm{zi}}}=\mathrm{e}^{\mathrm{zi}}$

From this equation, $\frac{p_{i}}{1-p_{i}}$ is the odds ratio in favour of being commercialized: the ratio of the probability that the farmers are included in the market participation or not included? The final Logit model is used in this study is the log odds ratio, which is linear both in parameters and independent variables. That is presented in the following manner:

$\mathrm{Li}=\ln \left(\frac{\mathrm{Pi}_{\mathrm{i}}}{\mathbf{1 - \mathrm { p } _ { \mathrm { i } }}}\right)=\mathrm{Zi}=\beta 1+\Sigma \beta \mathrm{XXi}$

Where, $\mathrm{L}=$ the $\log$ of odds ratio (linear in X's and parameters)

Therefore, the Logit model to be used for the estimation of the extent of commercialization/ market participation/ in this research as follows

$$
\begin{aligned}
M R K T P R N= & \beta 0+\beta 1 G N D+\beta 2 M R S T+\beta 3 R G N+\beta 4 E D N+\beta 5 F M L S S+\beta 6 F M E X \\
& +\beta 7 F R S Z+\beta 8 L O W+\beta 9 T R G+\beta 10 O F I N C+\beta 11 A C C D T+\beta 12 A C E X T \\
& +\beta 13 A C M K T I N+\beta 14 A C T R S P+\beta 15 A C I R R G+\beta 16 P R V+\beta 17 A C M D \\
& +e
\end{aligned}
$$

Where, MRKTPRN is market participation which is the dependent variable, $\beta 0$ is the constant term of the model $\beta 1-\beta 17$ denote the regression coefficients of the model, where, GND-Gender, MRST-Marital status, RGN-Religion, EDN-Education, FMLSS-Family size, FMEX-Farm experience , FMSZ-Farm size, LOWLandowner, TNG-Training, OFINC-Off farm income, ACCDT-Access to credit, ACEXT-Access to extension, ACMKTIN-Access to market Information, ACTRS-Access to transport, ACIRG-Access to irrigation, PRVPrice volatility and ACMD- Media \& Mobil.

\section{Result and Discussion}

\section{Assumption of Regression Analysis of the Variables}

To cheek the validities of the regression logistic model, the following Diagnostics Tests, such as autocorrelation which most important one and Omnibus Tests of Model Coefficients and Hosmer and Lemeshow test were also used to check model fitness and its validities.

\section{Autocorrelation}

The Durbin-Watson d statistics for this study which is presented below the table is 2.075 and it is approximately near to 2. Therefore, it can conclude that the autocorrelation assumption which is meeting the validities the uncorrelated that means residual terms are uncorrelated (Guajarati, 2004).

Table 1: Outcorrelation summary

\begin{tabular}{|c|l|l|c|c|l|}
\hline Model & R & R Square & Adjusted R Square & Std. Error of the Estimate & Durbin-Watson \\
\hline 1 & $.531^{\mathrm{a}}$ & 0.282 & 0.242 & 0.30182 & 2.075 \\
\hline
\end{tabular}

Source: SPSS survey output, 2019

2. Omnibus Tests of Model Coefficients

Table2: Omnibus Tests of Model Coefficients

\begin{tabular}{|l|l|c|c|c|}
\hline \multicolumn{2}{|c|}{} & Chi-square & Df & \multicolumn{1}{c|}{ Sig. } \\
\hline \multirow{3}{*}{ Step 1 } & Step & 133.564 & 19 & 0.000 \\
\cline { 2 - 5 } & Block & 133.564 & 19 & 0.000 \\
\cline { 2 - 5 } & Model & 133.564 & 19 & 0.000 \\
\hline
\end{tabular}

Source: SPSS survey output, 2019

The Omnibus Tests of Model Coefficients presented indicated that the overall indication of how well the model performs as compared to a model with none of the predictors entered. This is referred to as a 'goodness of fit' test. For this study sig. value which is less than 0.05 i.e. 0.000 values. Therefore, the model with set of variables used as predictors on SPSS's indicated the validities of the data, which assumed that each farmers are participated for commercialization and it is reported as a chi-square value of 133.564 with 19 degrees of freedom (Pallant, 2011).

3. Hosmer and Lemeshow Test

Table3: Hosmer \&Lemeshow test

\begin{tabular}{|c|c|c|c|}
\hline Step & Chi-square & Df & Sig. \\
\hline 1 & 3.728 & 8 & 0.881 \\
\hline
\end{tabular}

Source: SPSS survey output, 2019

The Hosmer and Lemeshow measure of overall fitness of the data which is significance value greater than .05 indicating the existence of significant difference between the observed and predicted value, and it supports 
models fitness. For this study the chi-square value for the Hosmer-Lemeshow Test is 3.728 with a significance level of .881. This value is greater than 0.05, therefore indicating support for the model (Pallant, 2011; Hair et al., 2010; and Tabachnick and Fidell, 2007).

4. Model Summary, Table 4: Model summary

\begin{tabular}{|l|c|c|c|}
\hline \multicolumn{3}{|c|}{ Model Summary } \\
\hline Step & -2 Log likelihood & Cox \& Snell R Square & Nagelkerke R Square \\
\hline 1 & $156.255^{\mathrm{a}}$ & 0.311 & 0.561 \\
\hline
\end{tabular}

a. Estimation terminated at iteration number 8 because parameter estimates changed by less than .001 .

Source: SPSS survey output, 2019

The above Model Summary table 4 indicated that the $\mathbf{- 2}$ Log Likelihood statistics is 156.255 \& the Model Summary provided the information about the usefulness of the model. The Cox \& Snell R Square and the Nagelkerke R Square values provide an indication of the amount of variation in the dependent variable explained by the model / independent variables. In this study, the two values are 0.311 and 0.562 ; provide that between 31.1 percent and 56.1 per cent of the variability is explained by this set of variables (Pallant, 2011). The model contained nineteen independent variables ( Gender, Marital status, Religion, Education, Family size, Farm experience, Farm size, Landowner, Training, Off farm income , Access to credit, Access to extension, Access to market, information, Access to transport, Access to irrigation, Access to private transportation, Price volatility, Media \& Mobile). As indicated in the above table the full model containing all predictors was statistically significant, $\chi 2(19, \mathrm{~N}=359)=133.564, p<.001$ which is indicating that the model was able to distinguish between respondents who are commercialized and not commercialized their agricultural products. This model explained as between 31.1\% (Cox and Snell R square) and 56.17\% (Nagelkerke R squared) of the variance in market participation status

Binary Logistic Regression Estimation Result

Table5: Binary Logistic Regression Estimation Result

\begin{tabular}{|c|c|c|c|c|c|c|c|c|}
\hline \multirow[t]{2}{*}{ Variables } & \multirow[t]{2}{*}{ B } & \multirow[t]{2}{*}{ S.E. } & \multirow[t]{2}{*}{ Wald } & \multirow[t]{2}{*}{ Df } & \multirow[t]{2}{*}{ Sig. } & \multirow[t]{2}{*}{$\operatorname{Exp}(B)$} & \multicolumn{2}{|c|}{ 95\% C.I.for EXP(B) } \\
\hline & & & & & & & Lower & Upper \\
\hline Gender & -0.333 & 0.579 & 0.331 & 19 & 0.565 & 0.717 & 0.230 & 2.229 \\
\hline Marital Status & -1.827 & 0.657 & 7.738 & 119 & .005 & 0.161 & 0.044 & 0.583 \\
\hline Religion & -2.032 & 1.430 & 2.020 & 119 & 0.155 & 0.131 & 0.008 & 2.160 \\
\hline Education & 0.847 & 0.301 & 7.927 & 19 & 0.005 & 2.332 & 1.293 & 4.205 \\
\hline Family size & -0.502 & 0.146 & 11.875 & 119 & 0.001 & 0.605 & 0.455 & 0.805 \\
\hline Farm experience & -0.013 & 0.019 & 0.480 & 119 & 0.488 & 0.987 & 0.951 & 1.024 \\
\hline Farm size & 2.422 & 0.506 & 22.934 & 119 & 0.000 & 11.263 & 4.181 & 30.344 \\
\hline Landowner & 0.203 & 0.244 & 0.690 & 119 & 0.406 & 1.225 & 0.759 & 1.977 \\
\hline Training & 3.087 & 0.634 & 23.722 & 119 & 0.000 & 0.046 & 0.013 & 0.158 \\
\hline Off farm income & -1.513 & 0.470 & 10.350 & 19 & 0.001 & 0.220 & 0.088 & 0.554 \\
\hline Access to credit & -0.568 & 0.469 & 1.466 & 119 & 0.226 & 0.567 & 0.226 & 1.421 \\
\hline Access to extension & 4.329 & 0.919 & 22.186 & 19 & 0.000 & 13.856 & 12.523 & 459.488 \\
\hline Access to market information & 1.878 & 0.508 & 13.674 & 119 & 0.000 & 6.539 & 2.417 & 17.692 \\
\hline Access to transport & -0.759 & 0.438 & 3.000 & 119 & 0.083 & 0.468 & 0.198 & 1.105 \\
\hline Access to irrigation & 1.993 & 0.600 & 11.035 & 19 & 0.001 & 7.340 & 2.264 & 23.792 \\
\hline Access to private transportation & 4.374 & 1.115 & 15.400 & 119 & 0.000 & 14.392 & 8.932 & 705.667 \\
\hline Price volatility & 2.534 & 0.788 & 10.347 & 119 & 0.001 & 12.602 & 2.691 & 59.012 \\
\hline Media & 0.163 & 0.471 & 0.119 & 119 & 0.730 & 1.177 & 0.468 & 2.960 \\
\hline Mobile & 0.810 & 0.460 & 3.104 & 119 & 0.078 & 2.249 & 0.913 & 5.538 \\
\hline Constant & -0.509 & 2.282 & 0.050 & & 0.823 & 0.601 & & \\
\hline
\end{tabular}

Discussion on Result of Logistic Regression

Among the nineteen independent variables( predictors), the following have significant impacts in the logistic regression, these are, marital status, education, family size, farm size, training, off farm income, access to extension, price volatility, access to irrigation, access to private transportation $\&$ access to market information.

Accordingly, the contribution of each significant explanatory variable is discussed with its empirical evidence. The $B$ value which indicates the direction of relationship and the $\operatorname{Exp}(\mathrm{B})$ value indicating the odds ratio/likelihood small holder framers being commercialized their agricultural products in the market/as well as the $P$ value showing the level of significant for each independent variables which used for discussion purpose

Therefore, the following discussion are lined up with $\mathrm{p}$ values are less than $5 \%$ which affect agricultural products of commercialization of a small holder farmers.

Marital Status: the above table 5indicated that marital status has statistically negative impact on commercialization of agricultural products with $\mathrm{p}$ value of 0.005 and odd ratio of 0.717 which implies that those 
individuals who are not engaged (in relations) are 0.717 times less likely to commercialize their products than those who are engaged, this means that if the farmers are engaged in relation, they are more participated on commercialization of agricultural products. It is supported by Tabitha and Tisdell (2003). Education: Education is one of the primary factors that affect the commercialization of agricultural products; the above table 5indicated that education has positive significant impact on commercialization with $p$ value of 0.005 and odd ratio of 2.332. The implication is that those who are educated were 2.332 times more likely than those who were not educated in commercialization of their agricultural products. This study was supported by the following empirical studies such as(Tolno et al. 2015, as cited by Kabiti et al., 2016; Abdullah et al., 2017). Family size: The results of above table 5,the logistic regression output indicated thatfamily size has negative significant impact on commercialization of agricultural products with $p$ value of 0.001 and odd ratio of 0.605 . This implies that those who have large families are 0.0605 times less likely than those who have low family on market participation (commercialization) of their agricultural products. This finding is supported by many empirical evidences (begallo, 2016; Abdullah et al., 2017, and Agwu, Anyanwu, and Mendie, 2012). Farm size: it is the main determinant on commercialization of agricultural products, thus the above table 5 indicated that farm size is statistically positive significant impact on commercialization of agricultural products with $\mathrm{p}$ value of 0.000 and odd ratios of 11.263, this implies that large farm size holders are 11.263 times more likely to commercialize their products than small farm land holders. In other words, these implication implies that farm size increased, productivity increased and lead to improvement of commercialization of agricultural products ( Martey, 2014; Birhanu and Haji, 2017; Olanrewaju \&Emilola, 2015 and Bogale, 2009). Training: It has positive significant impact on commercialization of agricultural products with the $\mathrm{p}$ values 0.000 and the odd ratio of 0.046 . This means that, those farmers who have got training is 0.046 more likely than those who have not got training on commercialization of agricultural products. it supported by the following findings such as, (Abdullah et al., 2017); Dube\&Guveya, 2016; Ruth et al.,2016; and Gashaw\& Bernard, 2017), on the contrary Bola et al., (2016) confirmed that attending at least one training session is positive and statistically significant in influencing for producing agricultural products. However, the number of training sessions attended has a negative and statistically significant effect on the intensity of on adoption among the lowland farmers this means that number of training is increased, the farmers nothing to add on commercialization if there is no new innovation. Off farm Income: it has a negative statistical significant impact on commercialization with $p$ value of 0.001 and its odd ratios is 0.22 , These indicated that those who have off farm income are 0.22 times less likely than those who have not off farm income in commercialization of agricultural products which is in line with previous empirical studies (Jaleta et al.,2009; Alene et al., 2008; Martey et al.,2012; Omiti et al.,2009, and Rios et al., 2008, cited in Abdullah et al.,2017). On the contrary Alene et al. (2008) found that off-farm income is conducive to commercialization if it is invested in farm improvement and technologies. Access to Extension: According to the logistic regression output access to extension has statistically positive significant impact on market participation with $\mathrm{p}$ value of 0.000 and odd ratio of 13.856 and this implies that those farmers who have access to extensions are13.856 times more likely than those farmers who haven't access to extension for commercialization of their agricultural products. Extension services were significant factors contributing to the level of commercialization of smallholder farmsand Modernizing extension and improving market linkage can play a vital role in improving the opportunities of millions of farmers for seeking ways to improve the productivity of their farms and to improve their market performance(Martey, 2014; Rivera 2000; Berhanu et al, 2016, \&Kabit et al.,2016).Access to Market Information: it has positive significant impact on market participation of agricultural products for the farmers in the rural areas with p value of 0.000 and its odd ratio is 6.539 which implies that those farmers who have access to market information is 6.539 times more likely than those who did not got access to market information to market participation. Similarly, Oliver et al.(2016) argued that use of ICT tools (mobile phones) significantly and positively affected market participation, especially usage of mobile phone is becoming a major source of market information for the farmers to commercialization their farm products (Chanyalewet al., 2011; Barrett, 2008,\&Martey, 2014).Access to Irrigation: it has positive significant impact on commercialization of agricultural products with $p$ value of 0.001 and odd ratios of 7.34 which indicates that those who have access to irrigation are 7.34 times most likely to commercialize than those who did not use irrigation (Ranjita et al., 2009; Kabiti et al., 2016; and Dube1 and Guveya, 2016). Access to Private Transportation: it has statistically significant positive impact on market participation or commercialization with $\mathrm{p}$ value of 0.000 and its has the highest odd ratios of 14.392 which indicated that those respondents who have a private transport are 14.392 times more likely than those who have not private transportation on market participation or commercialization i.e private transportation has great impact for increasing of productivities to enhance commercializing of agricultural products (Kabiti et al., 2016).Price Volatility: it has positive significant effect with $p$ values of 0.001 and the odd ratios of 12.602 . This logistic output indicated that as the price of product is increased, the farmers are 12.602 times more likely to commercialize than if the price is decreased (Junior Davis, 2011).

N.B:- To summarize the above discussion: among statistical significant variables, hypothesis $1, \mathbf{4 ,} \mathbf{5 , 7 , 8 , 9 , 1 0 ,}$ 
$11,12,13,15 \& 17$ are accepted while hypothesis $2,36,14$ and 16 are rejected

\section{Conclusion and Recommendation}

The main objective of this study is to identify the factors that affect commercialization of agricultural products. Therefore; based on the findings from binary logistic regression result, it is possible to conclude that marital status, education, family size, farm size, training, off farm income, access to extension, access to irrigation, access to private transportation \& access to market information, price volatility have statistically significant impact on commercialization of agricultural products. The findings of this study have important practical implications for small holder farmers as well as for the government. Therefore, in order to make the farmers fully and effectively engaged on commercialization of agricultural products farmers should get access to education, adjusting family planning, facilitating farm size, providing training, addressing access to extension, access to irrigation, access to private transportation\& access to market information. In addition, different workshops should be organized for small holder farmers to share experience about commercialization of agricultural products.

\section{Limitations and Directions for Future Research}

A single study could not identify all possible solution on these areas so the major limitations include the usage of binary logistic regression than developing market participation index to measure the dependent variable (market participation/commercialization) and the usage of only primary data for data analysis and interpretation. Therefore, we recommend future researchers to consider the limitations of this research as a gap / opportunity/ while doing similar researches.

\section{REFERENCES}

Abdullah et al., (2017). Determinants of commercialization and its impact on the welfare of smallholder rice farmers by using Heckman's two-stage approach, Journal of the Saudi Society of Agricultural Sciences journal homepage.

Barrett, C. B. 2008. Smallholder market participation: concepts and evidence from eastern and southern Africa. Food Policy, 33(4): 299-317.

Bola, A., A., et al. (2016).Agricultural technology adoption, commercialization and smallholder rice farmers' welfare in rural Nigeria, Agricultural and Food Economics

Chanyalew et al., (2011).Factors Determining the Degree of Commercialization of Smallholder Agriculture.http://opendocs.ids.ac.uk/opendocs

Dixie, G. (1989).Horticultural Marketing: A Resource and Training Manual for Extension Officers, FAO Agricultural Services Bulletin, Food and Agricultural Organization of the United Nations, Rome, pp. 1-5.

Dube, L. and Guveya, E. (2016).Determinants of agriculture commercialization among smallholder farmers in Manicaland and Masvingo, Provinces of Zimbabwe. Agricultural Science Research Journal Vol. 6(8): 182 $-190$.

Edward, M., (2014). Market Information and Extent of Agricultural Commercialization: Empirical Evidence from Smallholder Farmers in Effutu Municipality of Ghana, American Journal of Experimental Agricultur .www.sciencedomain.org.

Ellis, F. (2000). Rural livelihoods and diversity in developing countries.Oxford University Press.

Gebreslassie, H., Kebede, M., and Kiros, M., (2015).Crop commercialization and smallholder farmers' livelihood in Tigray region, Ethiopia.Journal of Development and Agricultural Economics. Vol. 7(9), pp. 314-322, September, 2015. DOI: 10.5897/JDAE2015.0649

Goletti, F. (2005). Agricultural Commercialization, value chains and poverty reduction, In: Making Markets Work Better for the Poor, ADB/DfID. Agricultural food Consulting International.

Govereh, J., Jayne, T.S and Nyoro, J. (1999).Smallholder Commercialization, Interlinked Markets and Food Crop Productivity: Cross Country Evidence in Eastern and Southern Africa, the Department of Agricultural Economics and the Department of Economics, Michigan State University, June 1999.

H.M. Kabiti, et al.(2016). Department of Agricultural Economics and Agribusiness, University of Venda, P Bag X5050,University Road, Thohoyandou, 0950, Limpopo Province, South Africa, E-mail: 1khazamula.chauke@univen.ac.za.

Jayne, T., Mather, D., Mghenyi, E. (2005). Smallholder farming in difficult circumstances: policy issues for Africa. Future Small Farms 103.

Kabiti, H.M, Raidimi, N.E., Pfumayaramba, T.K., and Chauke, P.K. (2016). Determinants of Agricultural Commercialization among Smallholder Farmers in Munyati Resettlement Area, Chikomba District, Zimbabwe. J Hum Ecol, 53(1): 10-19.

Kothari (2004), Research Methodology - Methods and Techniques

Kriesberg, M.(1974) . "Marketing Efficiency In Developing Countries”. In: Marketing Systems For Developing 
Countries. (Eds.)

Leykun, B. and Jemma, H.(2017).Econometric Analysis of Factors Affecting Market participation of Smallholder Farming in Central Ethiopia Online at https://mpra.ub.uni-muenchen.de/77024/ MPRA Paper No. 77024, posted 28 February 2017 17:21 UTC

Lighton.D, and Emmanuel. G,( 2016). Determinants of agriculture commercialization among smallholder farmers in Manicalandand Masvingo Provinces of Zimbabwe, Agricultural Science Research Journal Vol. 6(8): 182 - 190, August 2016 Available online at http://resjournals.com/journals/agricultural-scienceresearch-journal.html ISSN: 2026 -6073 C2016 International Research Journals.

Begallo, F.J. (2016). Status determinants and effect of agriculture Commercialization among smallholder farmers in Tanzania.

Martey.E, Etwire. P, Wiredu AN, Wahaga.E., Unpublished (2012). Report on Baseline Survey of Sweet Potato Farmers in Northern Ghana under the project. Horticulture CRSP Focus Project STOPS: Sustainable Technologies for Orange and Purple Sweet Potatoes in Ghana. Report Prepared for Pennsylvanian State University; 2013.

N.M. Agwu, C.I. Anyanwu\& E.I. Mendie,(2012). Socio-Economic Determinants of Commercialization among Small Holder Farmers, Greener Journal of Agricultural Sciences ISSN: 2276-7770 Vol. 2 (8), pp//392-397

Olanrewaju\&Emilola (2015). Agricultural Commercialization: Effect on Food Security among Smallholder Farming Households in Southwestern Nigeria International Journal of Science and Research (IJSR) ISSN (Online): 2319-7064 Index Copernicus Value (2015): 78.96 | Impact Factor (2015): 6.391.

Oliver, K. Kirui, Georgina.W, Njiraini, (2016 ). Determinants of agricultural commercialization among the rural poor: The Role of ICT and Collective Action Initiatives and gender perspective in Kenya,pp//1753.

Pingali, P.L., Rosegrant, M.W., 1995. Agricultural commercialization and diversification: processes and policies. Food Policy 20 (3), 171-185.

Ranjita, N.Gopal, B. Thapa (2009).Determinants of agricultural commercialization and mechanization in the hinterland of a city in Nepal,journal homepage: www.elsevier.com/locate/apgeog

Rivera, W.M.,(2000). The Changing Nature of Agricultural Information and the Conflictive Global Developments Shaping Extension. Journal of Agricultural Education and Extension (Wageninen), 7:1, June 2000, 31-41.

Rosson, P. (1974). "Changing Traditional Distribution Systems: Fish Marketing In Tanzania”, Journal of Physical Distribution, No. 4, Vol. \%, pp.305-316.

Ruth . S, Laurenz.L, Natalie. R,Evans M., (2016).The effects of training ,innovation and new technology on Africa small holder farmer's economic outcomes and food security, international initiative for impact evaluation

Strasberg, P. J. et. al., Effects of agricultural commercialization on food crop input use and productivity in Kenya. MSU International Development Working Paper No. 71. East Lansing, MI, USA. 1999

Von Braun, J., Bouis, H., and Kennedy, E., (1994). Conceptual Framework, In: Agricultural Commercialization, Economic Development and Nutrition, Chapter 2, Von Braun and Kennedy (eds), The Johns Hopkins University Press, Lond 